\title{
Epithelioid sarcoma with multiple lesions on the left arm: a case report
}

\author{
Rie Nishibaba ${ }^{*}$, Yuko Higashi $^{1}$, Yuko Goto ${ }^{2}$, Masanori Hisaoka ${ }^{3}$ and Takuro Kanekura ${ }^{1}$
}

\begin{abstract}
Background: Epithelioid sarcoma is a rare, high-grade malignant tumor of the soft tissue. The incidence of local recurrence, regional lymph node involvement, and distant metastases is high. Epithelioid sarcoma is most often seen in adolescents and young adults. In the early stage before the development of full clinical features, epithelioid sarcoma is often misdiagnosed as a benign disease such as granuloma.

Case presentation: We report a case of a 74-year-old Japanese woman whose epithelioid sarcoma was initially misdiagnosed as fungal infection. Rebiopsy revealed the proliferation of atypical polygonal or oval epithelioid cells in the dermis and lymphocyte infiltration through the dermis. Immunohistochemically, the tumor cells were positive for vimentin, cell adhesion molecule 5.2, epithelial membrane antigen, and E26-related gene. The nuclear expression of integrase interactor 1 was lost in the tumor cells.
\end{abstract}

Conclusions: We encountered a rare case of epithelioid sarcoma and had difficulty in making the correct diagnosis. We suggest that in patients whose lesions are resistant to conventional treatments, repeat biopsy and immunohistochemical studies should be considered to rule out rare epithelioid sarcoma.

Keywords: CA-125, Epithelioid sarcoma, E26-related gene, Integrase interactor 1, Malignant soft tissue tumor

\section{Background}

Epithelioid sarcoma (ES), first described by Enzinger in 1970 [1], is a rare sarcoma localized to deep or superficial soft tissue. It is the most common soft tissue sarcoma of the hand and wrist, followed by alveolar rhabdomyosarcoma and synovial sarcoma. ES can develop at any age but is rarely seen in children and the elderly. Because it is very rare and appears to be a benign lesion in the early stage, ES is often misdiagnosed as a benign disease such as granuloma. We report a case of a patient with ES on the hand and forearm with multiple satellite cutaneous lesions.

\section{Case presentation}

A 74-year-old Japanese woman presented to our hospital with multiple ulcerated nodules on the left hand and forearm. The nodules had slowly increased in size and number for 2 months. An examination revealed a $2-\mathrm{cm}$

\footnotetext{
* Correspondence: rie-k@m2.kufm.kagoshima-u.ac.jp

${ }^{1}$ Department of Dermatology, Kagoshima University Graduate School of Medical and Dental Sciences, 8-35-1 Sakuragaoka, Kagoshima 890-8520, Japan

Full list of author information is available at the end of the article
}

ulcerated nodule on her left hand; she had multiple satellite lesions on her left hand and forearm (Fig. 1a, b). The initial differential diagnoses included subcutaneous mycosis and malignant melanoma. Histopathological examination showed ulceration and granulomatous lesions with multinucleated giant cells in the deep dermis. A periodic acid-Schiff stain revealed no fungi in the specimen, but a tissue culture was positive for Alternaria, a dematiaceous fungus. A diagnosis of dermal cutaneous alternariosis was made. The patient was started on itraconazole therapy, but her nodules increased in size and number within the next 2 months. Rebiopsy of a nodule on the patient's palm revealed the proliferation of atypical polygonal or oval epithelioid cells in the dermis and lymphocyte infiltration through the dermis (Fig. 2). Immunohistochemically, the tumor cells were positive for vimentin, cell adhesion molecule 5.2 (CAM5.2), epithelial membrane antigen (EMA), and E26-related gene (ERG) (Fig. 3a-c); they were negative for AE1/AE3, CD34, S100, smooth muscle actin, and CD31. The nuclear expression of integrase interactor 1 (INI1) was lost in the tumor cells (Fig. 3d). 

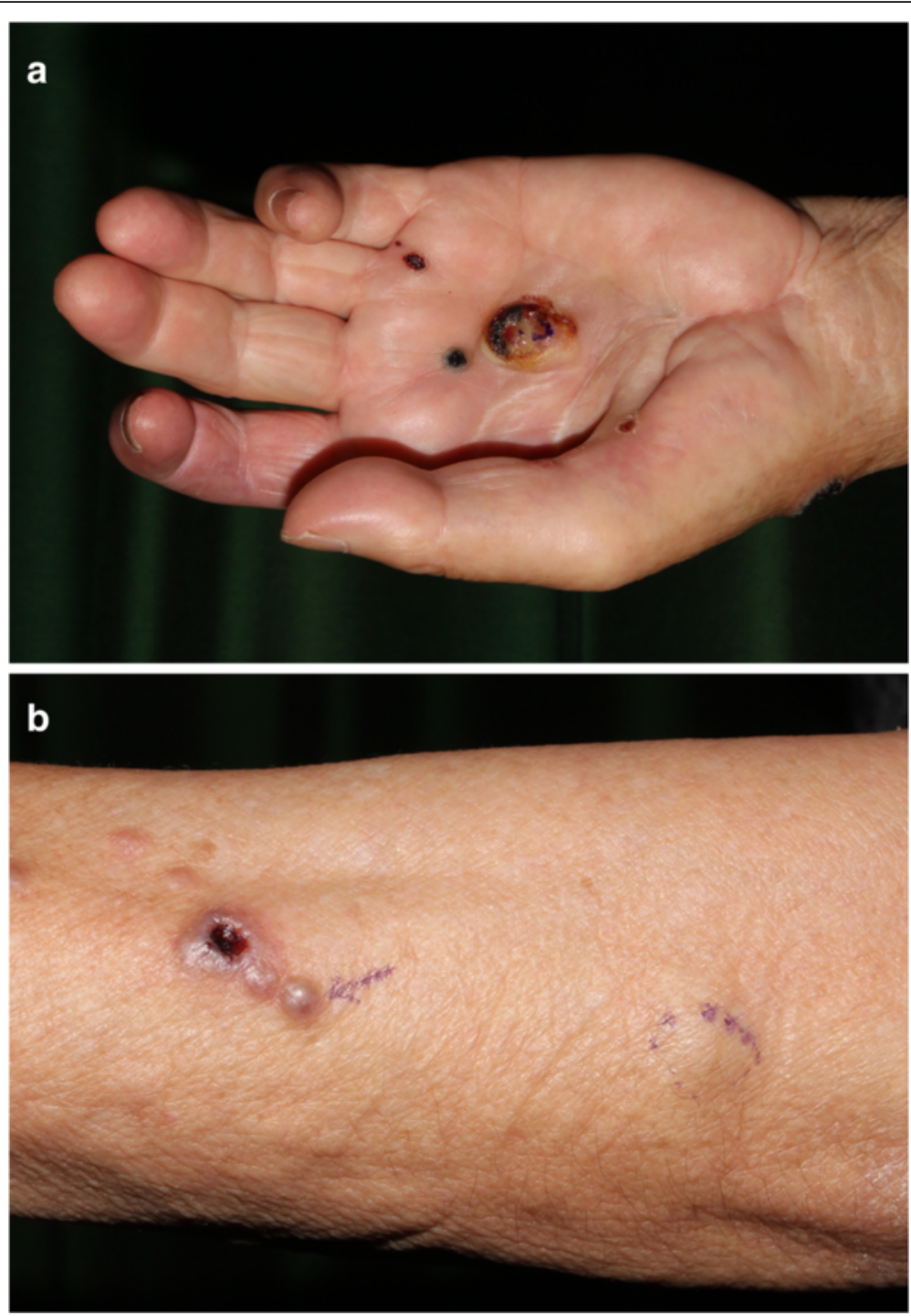

Fig. 1 a A 2-cm ulcerated nodule on the left hand. b Multiple lesions on the patient's left forearm

On the basis of these findings, a diagnosis of ES was made. Preoperative fluorodeoxyglucose-positron emission tomography showed elevated glucose levels in the multiple lesions on the patient's left hand, left forearm, and left axillary lymph nodes (Fig. 4). After shoulder disarticulation and axillary lymph node dissection, there was no recurrence, and no metastases were observed during 9 months of follow-up.

\section{Discussion}

ES, a rare and highly malignant soft tissue tumor, shows a high tendency for local recurrence, regional lymph node involvement, and distant metastases [1]. ES constitutes less than $1 \%$ of all soft tissue sarcomas [2]. It is characterized clinically by a firm and slow-growing tumor with a predilection for the hands, fingers, and forearms. Fifty-four percent of cases arise in the distal upper extremities [2]. Pain or tenderness is rarely a prominent symptom, unless large nerves are affected by the tumor. ES is commonly seen in young patients; the peak incidence is in the third decade of life, and it is rare in children and the elderly.

Recurrence and metastasis are reported in $77 \%$ and $45 \%$ of patients with ES, respectively. The most common sites of metastasis are the lungs (51\%), regional lymph nodes (34\%), scalp (22\%), and bone (13\%) [2]. ES is highly malignant; $32 \%$ of patients die as a result of the disease [3]. Male sex, proximal location, large tumor size (greater than $50 \mathrm{~mm}$ ), deep location, high mitotic index, hemorrhage, necrosis, vascular invasion, and inadequate initial excision causing local recurrence have been shown to be poor prognostic factors [4]. 


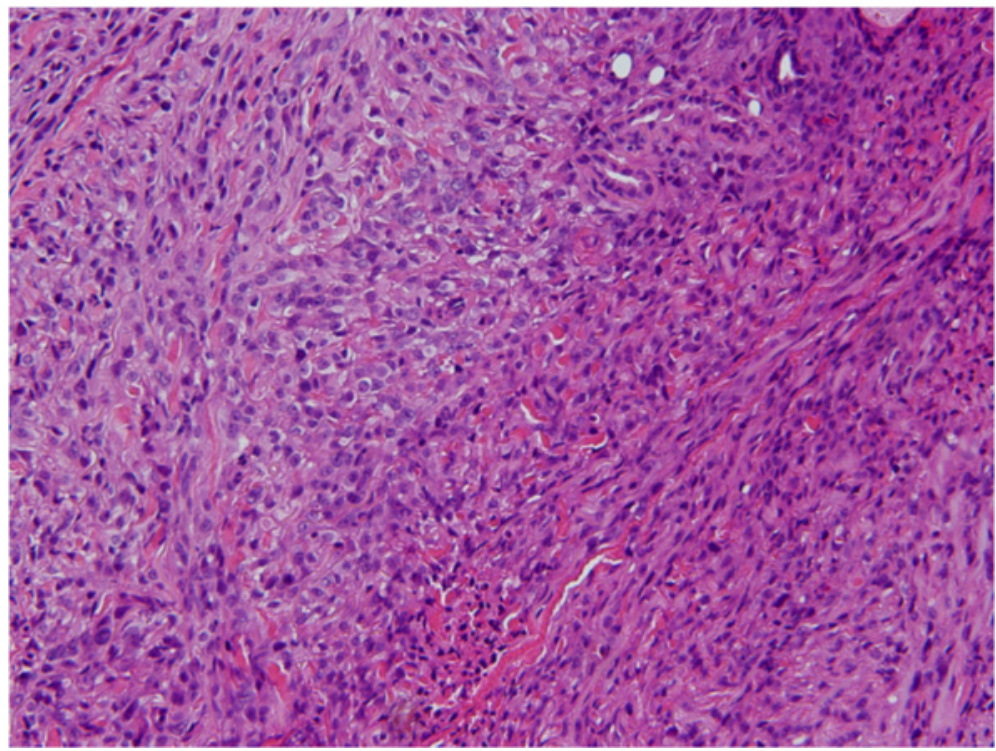

Fig. 2 Histopathological examination of a skin biopsy from a nodule on the palm. The lesion was composed of a proliferation of atypical polygonal or oval epithelioid cells in the dermis with lymphocytic infiltration through the dermis. Hematoxylin and eosin stain, original magnification $\times 200$

Clinical features of the reported cases are summarized in Table 1.

A new subtype, a proximal variant of ES, has been proposed [5]. This subtype exhibits more aggressive clinical behavior, and its histopathological appearance is distinct.
Clinically, the proximal subtype differs from the classical type by its multinodular growth pattern, its more frequent occurrence in older patients, its more proximal/axial distribution, its more deep-seated location, and its more aggressive clinical behavior from the outset. Histologically, it
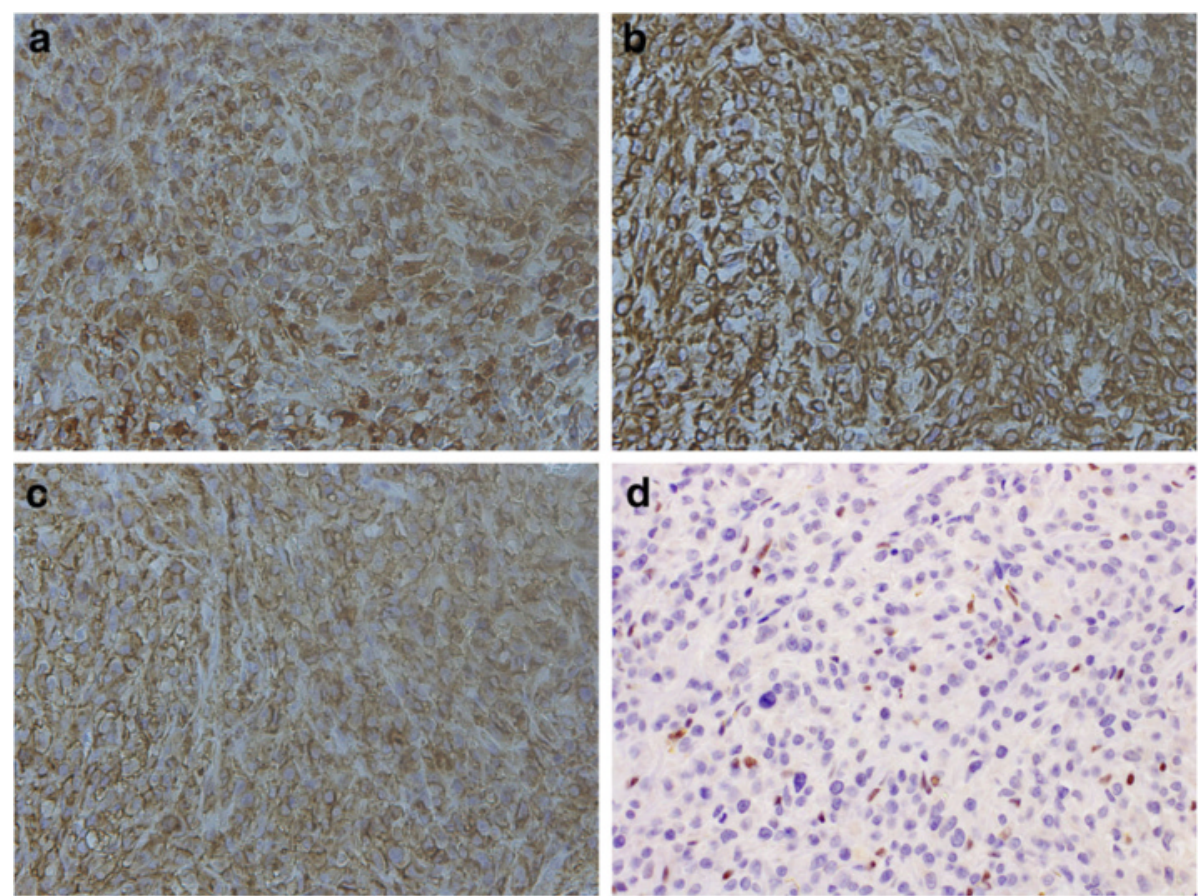

Fig. 3 Immunohistochemical staining for (a) vimentin, (b) cell adhesion molecule 5.2, and (c) epithelial membrane antigen. (d) The nuclear expression of integrase interactor 1 was diminished in the tumor cells 


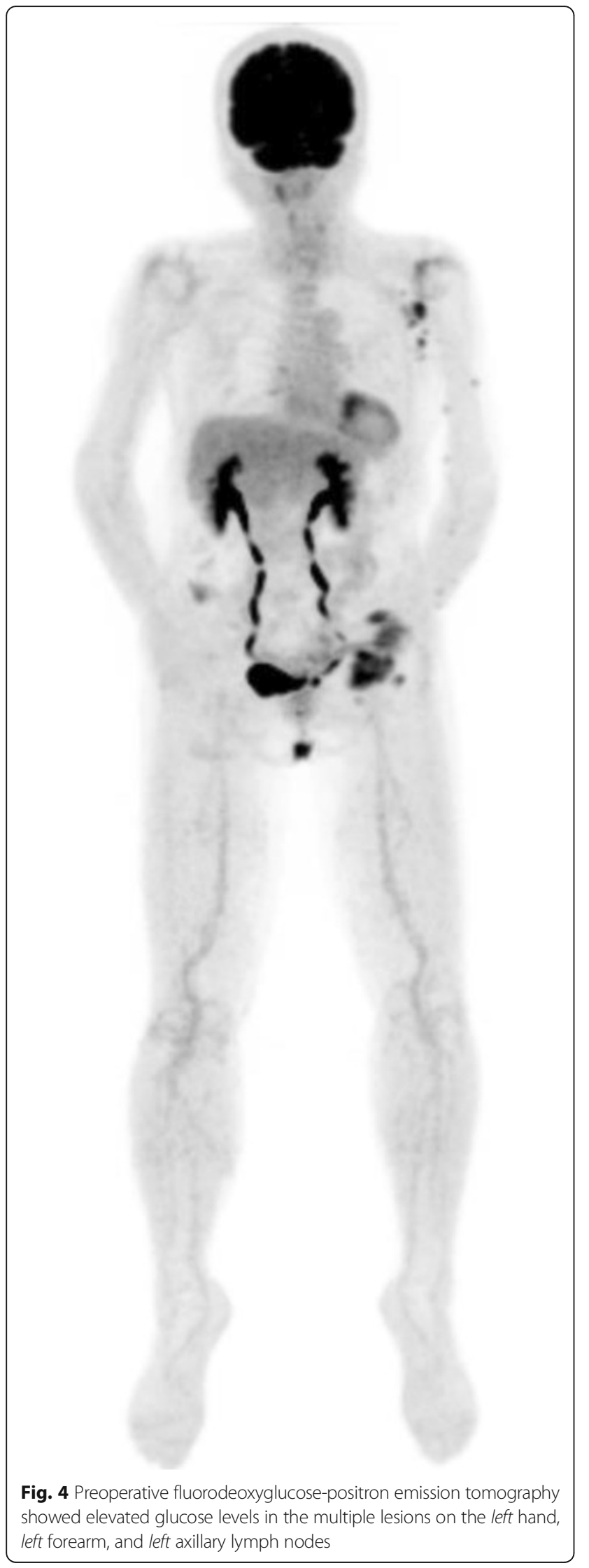

Table 1 Clinical features of previously reported cases and our patient

\begin{tabular}{lll}
\hline & Reported cases [5] & Our patient \\
\hline Male sex, \% & $42-79$ & - \\
Female sex, \% & $21-62$ & + \\
$\begin{array}{l}\text { Mean age at first symptoms, } \\
\text { years }\end{array}$ & $23-41$ & 74 \\
$\begin{array}{l}\text { Mean symptom duration before } \\
\text { diagnosis, months }\end{array}$ & $7.1-36$ & 4 \\
$\begin{array}{l}\text { Local recurrence, \% } \\
\text { Lymph node metastases, \% }\end{array}$ & $29-85$ & + \\
Distant metastases, \% & $11-65$ & + \\
& $21-62.5$ & - \\
\end{tabular}

is characterized by predominantly large cells, epithelioid cytomorphology, marked cytological atypia, the frequent manifestation of rhabdoid features, and the absence of a granuloma-like pattern in most patients. On the basis of our clinical and histological findings, we considered the ES in our patient to be of the conventional distal type.

The cellular elements of ES range from large ovoid or polygonal cells with deeply eosinophilic cytoplasm to plump, spindle-shaped cells [3]. Consequently, ES is often misdiagnosed as one of numerous benign and malignant disorders, and proper treatment is delayed. The median interval between the initial diagnosis and the start of treatment is 3.5 months (range 1-6 months) [6]. Nishimura et al. [7] reported a patient with ES masquerading as an intractable wound for more than 18 years. We correctly diagnosed our patient 4 months after her initial presentation.

Immunohistochemical examination is essential to making a diagnosis of ES. Characteristically, it shows expression of vimentin and low-molecular-weight cytokeratins such as those recognized by the monoclonal antibody CAM5.2 [8,9], and 85-96 \% of cases are EMA-positive [4]. The staining pattern suggests that ES is a neoplasm of mesenchymal origin with epithelial dedifferentiation. Vimentin is rarely negative. CD34, expressed in approximately $50 \%$ of ES lesions, is used as an additional diagnostic marker in vimentin-negative cases. The INI1 gene is a member of the adenosine triphosphate-dependent SWI/SWF chromatin-remodeling complex and thus a candidate as a tumor suppressor gene. Loss of the INI1 gene is seen in some patients with malignant rhabdoid tumors; its loss is $93 \%$ sensitive for a diagnosis of ES [10].

ERG, a member of the erythroblast transformationspecific family of transcription factors, is a marker of endothelial differentiation [11]. Kohashi et al. [12], who analyzed the expression of ERG in INI1-deficient tumors, including ES, reported that ERG was expressed in 13 of 24 conventional distal type lesions and 5 of 20 patients with proximal-type ES. All of their patients with 
malignant rhabdoid tumors had negative test results for ERG, suggesting that ERG may be a useful marker to distinguish ES from malignant rhabdoid tumors with loss of INI1.

Cancer antigen 125 (CA-125) is a high-molecularweight glycoprotein commonly used for the identification of epithelial ovarian carcinomas; it has also been detected in various neoplasms, including carcinomas of the breast, lung, and colon, and in patients with lymphoma. Kato et al. [13] documented that 10 (91\%) of 11 patients with ES had positive test results for CA-125; 10 manifested the classical type and the other had the proximal type of the disease. In other soft tissue tumors, including synovial sarcomas, clear cell sarcomas, leiomyosarcomas, rhabdomyosarcomas, liposarcomas, malignant peripheral nerve sheath tumors, malignant fibrous histiocytomas, desmoid tumors, cutaneous squamous cell carcinomas, and rheumatoid nodules, CA-125 was negative. Other authors $[8,9]$ have suggested that CA-125 immunoreactivity in the presence of an elevated serum CA-125 level could be a useful tumor marker for the diagnosis of ES and for monitoring the clinical course of patients with ES.

\section{Conclusions}

ES is very rare and appears to be a benign lesion in the early stage, and it is often misdiagnosed as a benign disease such as granuloma. We encountered a rare case of ES and had difficulty in making the correct diagnosis. We suggest that in patients whose lesions are resistant to conventional treatments, repeat biopsy and immunohistochemical studies should be considered to rule out rare ES.

\section{Acknowledgements}

We sincerely thank our patient for allowing us to publish this case report.

\section{Funding}

No funding agency was involved in our patient's treatment or our preparation of the manuscript.

\section{Availability of data and materials}

The dataset supporting the conclusions of this case report is included within the case report (images and laboratory parameters).

\section{Authors' contributions}

$\mathrm{RN}, \mathrm{YH}$, and TK carried out medical management and the writing of the manuscript. YG and $\mathrm{MH}$ performed the histological examination of the patient's skin biopsy. All authors read and approved the final manuscript.

\section{Competing interests}

The authors declare that they have no competing interests.

\section{Consent for publication}

Written informed consent was obtained from the patient for publication of this case report and any accompanying images. A copy of the written consent is available for review by the Editor-in-Chief of this journal.

Ethics approval and consent to participate Not applicable.

\section{Author details}

'Department of Dermatology, Kagoshima University Graduate School of Medical and Dental Sciences, 8-35-1 Sakuragaoka, Kagoshima 890-8520, Japan. ${ }^{2}$ Department of Pathology, Field of Oncology, Kagoshima University Graduate School of Medical and Dental Sciences, Kagoshima, Japan.

${ }^{3}$ Department of Pathology and Oncology, School of Medicine, University of Occupational and Environmental Health, Kitakyusyu, Japan.

Received: 25 January 2016 Accepted: 4 October 2016

Published online: 24 October 2016

\section{References}

1. Enzinger FM. Epithelioid sarcoma: a sarcoma simulating a granuloma or a carcinoma. Cancer. 1970;26:1029-41.

2. Chase DR, Enzinger FM. Epithelioid sarcoma: diagnosis, prognostic indicators, and treatment. Am J Surg Pathol. 1985;9:241-63.

3. Enzinger FM, Weiss SW. Malignant soft tissue tumors of uncertain type. In: Weiss SW, Goldblum JR, editors. Enzinger and Weiss's soft tissue tumors. 4th ed. St. Louis, MO: Mosby-Year Book; 2001. p. 1521-38.

4. Coates SJ, Ogunrinade O, Lee HJ, Desman GJ. Epidermotropic metastatic epithelioid sarcoma: a potential diagnostic pitfall. Cutan Pathol. 2014;41(8):672-6.

5. Guillou L, Wadden C, Coindre JM, Krausz T, Fletcher CD. "Proximal-type" epithelioid sarcoma, a distinctive aggressive neoplasm showing rhabdoid features: clinicopathologic, immunohistochemical, and ultrastructural study of a series. Am J Surg Pathol. 1997;21:130-46.

6. de Visscher SA, van Ginkel RJ, Wobbes T, Veth RP, Ten Heuvel SE, Suurmeijer AJ, et al. Epithelioid sarcoma: still an only surgically curable disease. Cancer. 2006;107(3):606-12.

7. Nishimura Y, Yamaguchi Y, Tomita Y, Hamada K, Maeda A, Morita A, et al. Epithelioid sarcoma on the foot masquerading as an intractable wound for $>18$ years. Clin Exp Dermatol. 2010;35(3):263-8.

8. Lynch MC, Graber EM, Johnson TS, Clarke LE. Epithelioid sarcoma resembling benign fibrous histiocytoma. Cutis. 2015;95(2):83-6.

9. Armah HB, Parwani AV. Epithelioid sarcoma. Arch Pathol Lab Med. 2009; 133(5):814-9.

10. Hornick JL, Dal Cin P, Fletcher CD. Loss of INI1 expression is characteristic of both conventional and proximal-type epithelioid sarcoma. Am J Surg Pathol. 2009;33(4):542-50.

11. Martens JH. Acute myeloid leukemia: a central role for the ETS factor ERG. Int J Biochem Cell Biol. 2011;43(10):1413-6.

12. Kohashi K, Yamada Y, Hotokebuchi Y, Yamamoto H, Taguchi T, Iwamoto Y, et al. ERG and SALL4 expressions in SMARCB1/INI1-deficient tumors: A useful tool for distinguishing epithelioid sarcoma from malignant rhabdoid tumor. Hum Pathol. 2015;46(2):225-30.

13. Kato H, Hatori M, Kokubun S, Watanabe M, Smith RA, Hotta T, et al. CA125 expression in epithelioid sarcoma. Jpn J Clin Oncol. 2004;34(3):149-54.
Submit your next manuscript to BioMed Central and we will help you at every step:

- We accept pre-submission inquiries

- Our selector tool helps you to find the most relevant journal

- We provide round the clock customer support

- Convenient online submission

- Thorough peer review

- Inclusion in PubMed and all major indexing services

- Maximum visibility for your research

Submit your manuscript at www.biomedcentral.com/submit
) Biomed Central 